Colloque C3, suppl. au Journal de Physique III, Vol, 1, octobre 1991

\title{
IMPACT BEHAVIOUR OF CARBON FIBER REINFORCED COMPOSITES UNDER BEND LOADING CONDITIONS
}

\author{
F.-J. BEHLER ${ }^{*}$ and S. SIKORSKI* * \\ * Fraunhofer-Institut für Angewandte Materialforschung, Abt. \\ WBV/Faserverbundstrukturen, Lesumer Heerstrasse 36, D-2820 \\ Bremen 77, Germany \\ * Motoren-und Turbinen-Union München GmbH, Abt. ELN-Nr. \\ 016-90M, Dachauer Strasse 665, D-8000 München 50, Germany
}

\begin{abstract}
Résumé - Nous donnons un récapitulatif des propriétés attendues des matériaux composites, lorsqu'il sont soumis à des chargements intenses et brefs engendrant des vitesses de déformations élevées. Nous présentons une technique d'essai pour la caractérisation mécanique au choc, et nous présentons quelques résultats expérimentaux.
\end{abstract}

Abstract - A review on the requirement of the mechanical behaviour of composite materials under high strain rate and impact loading conditions is given. A technique for the determination of the mechanical behaviour is described and some data and experimental results are presented.

\section{Introduction}

In a wide range of technical applications, loading-profiles and potential damage development of complex structural components are tried to be described by numerical simulation beforehand. A number of attempts has been made to apply finite element methods to the modelling of high strain rate and impact response of composite materials and structures $/ 1 /$.

The numerical simulation requires - in addition to a soft- and hardware input, and the know-how on basic design with regard to the special problems of non-isotropicity, and two or more phases - characteristic mechanical materials data. This data have to be evaluated under loading conditions, as close as possible to the loading conditions of the real structural components, with the aim to give a basic safety in construction and design.

\section{Material Behaviour and Loading Condition}

strength and deformability of materials are strongly influenced by the loading conditions, e.g.

- temperature

- stress state

- strain rate.

The influence of temperature is well known for a large number of materials, for example a drop down of deformability with decreasing temperature, and a decreasing strength with increasing temperature for 
steels, the influence of the stress state can be considered by some analytically based models (von Mises, Tresca etc). The knowledge on the mechanical properties of materials under impact and high rates of strain, especially in the field of advanced fiber reinforced materials is rather incomplete.

Different temperatures cause different material properties but don't cause principly different internal loading conditions. This is in opposition to the influence of strain rate and impact phenomena. An increasing strain rate - starting from the creep area over quasistatic conditions to the high strain rate and impact region - effects a change in the internal loading condition from a global to a local one, $/ 2 /$.

For design and construction in the region of low strain rates stiffness, fatique strength and elastic deformation are the main characteristic values. Under extremely high loading rate- and impactconditions other problems are placed into the foreground like contact problems, shock-wave phenomena, spalling and hydrodynamic material flow. These different modi of internal loading have to be taken into consideration by the application of computer software/programs for the numerical simulation of high rate loading processes of structural components.

\section{Impact, High strain Rate Properties}

The testing of materials and components under impact loading conditions gives information on

- damage, damage evolution, damage area

- energy consumption

- strength after impact, fig. 1.

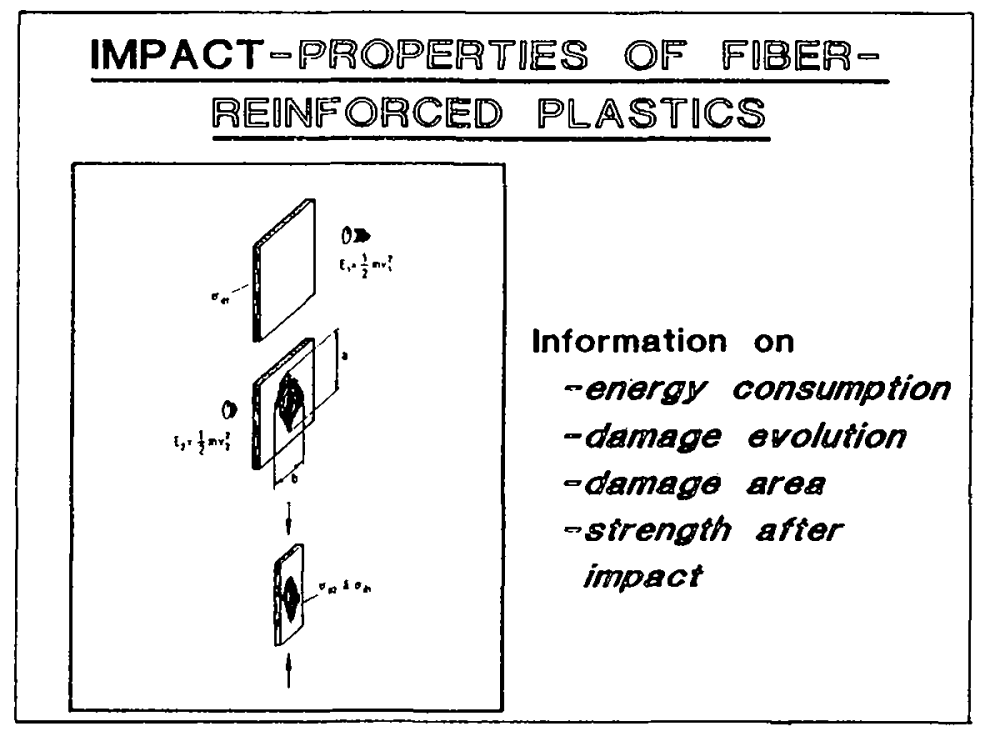

fig. 1: Information of testing materials under impact loading conditions

High strain rate testing delivers the mechanical properties needed for design, construction and numerical simulation:

- yield 
- strength

- elongation to fracture, fig. 2 .

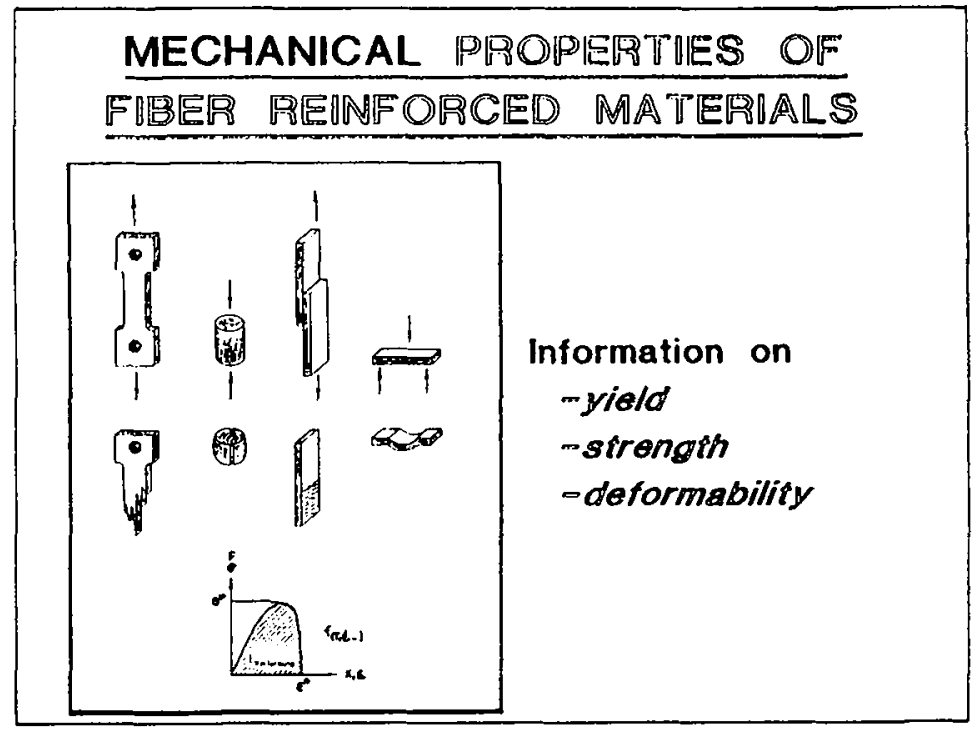

fig. 2: Information of testing materials und high strain rate conditions

Caused by the requirements of design one has to secure a minimum of deformability with regard to strain rate and temperature effects and so to prevent a catastrophic damage evolution.

\section{Fiber Reinforced Materials}

Fiber reinforced materials are in a preferred application where its non-isotropic properties high stiffness, high strength and low density can lead to a high quality design. Crucial areas of every design are the loading points. These advanced materials are not able to reduce local stress peaks by local flow as metallic materials do.

\section{High strain Rate Testing of Composite Materials}

Investigations on some fiber reinforced materials were carried out by a number of research-institutes. Different testing techniques are in application to get characteristic values and to create a source of basic material properties for design and numerical simulation.

A number of results of different investigations with the use of different testing techniques was summarized, fig. $3, / 3$ to 6/. The general shape of all plots shows an increasing strength with increasing strain rate independently from testing technique and loading condition.

Most of these investigations are performed on glassfiber reinforced plastics and on woven material qualities. Also glass/carbon hybrides were tested under different strain rates, fig. 4, /7/. Proceeding from the all-glass-fiber quality a distinct increase of stiffness and strength can be noticed with increasing fraction of carbon-fibers and strain rate. 


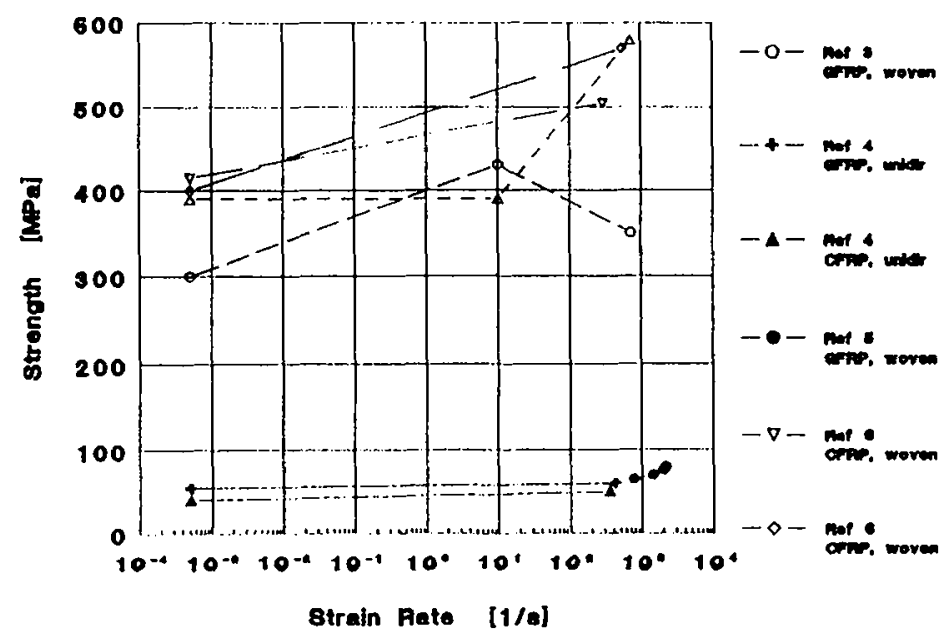

fig. 3: Strain rate dependent properties of some fiber reinforced plastics (/3 to $6 /)$

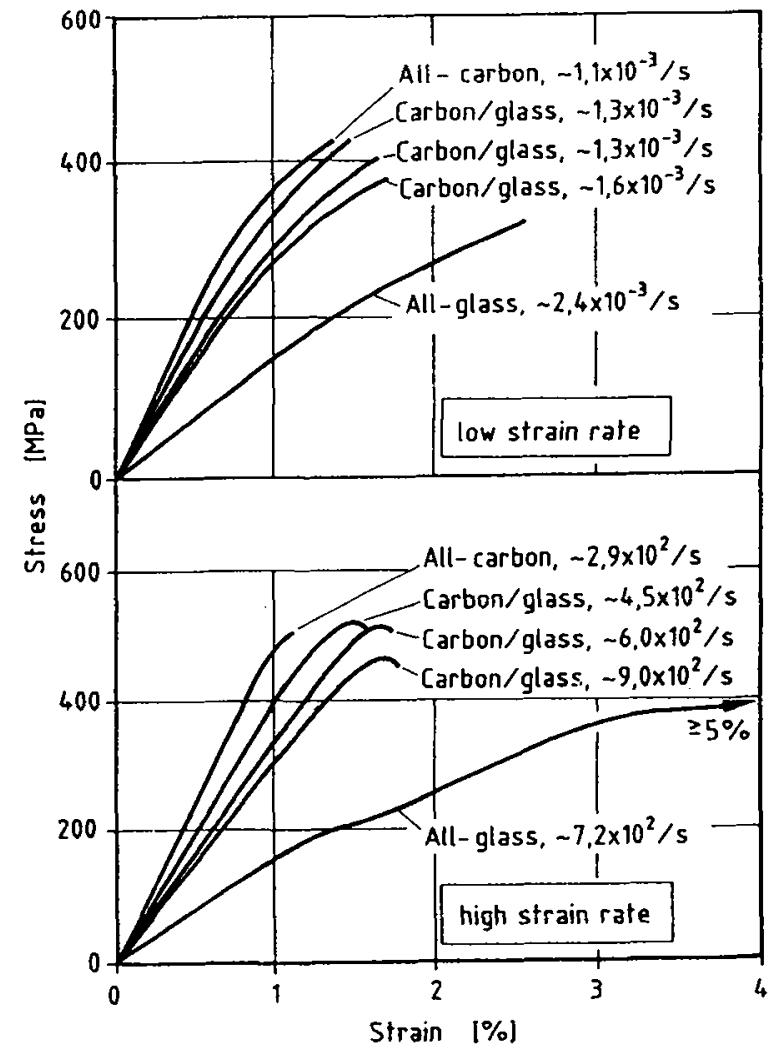

fig. 4: Glass/carbon hybrids, stress-strain plots, influence of loading rate (Harding /7/) 


\section{High strain Rate Bend Tests on Different Qualities of CFRP}

The wider establishment of advanced carbon fiber reinforced materials in the field of highly loaded engine- and structural components requests the knowledge of its mechanical properties. Within this scope, three different CFRP-qualities

$$
\begin{aligned}
\text { 1.: } & \text { Epoxymatrix, Carbonfiber } \\
& \text { Vicotex } 6376, \mathrm{~T} 800 \text { fiber } \\
& 48 \text { layers, unidirectional }
\end{aligned}
$$

2.: Epoxymatrix, Carbonfiber

Vicotex $6376, T 800$ fiber

49 layers, $00+45009000-45$

3.: PEEK-Matrix, Carbonfiber

APC 2, IM 6 fiber

48 layers, unidirectional

were characterized under quasistatic and high strain rate loading conditions in a modified flying-wheel apparatus, $/ 8$. This apparatus enables to carry out cantilever bend tests in a strain rate range from $5 \cdot 10^{-3} \mathrm{~s}^{-1}$ to $10^{3} \mathrm{~s}^{-1}$. Using strain gages, fixed in the area of medium (pure elastic) and maximum bending moment this technique delivers stress-time- and strain-time-diagrams from which stress-straindiagrams can be evaluated by the elimination of time, $/ 9 /$.

\section{Results}

The investigated different qualities of carbon fiber reinforced plastics show a coherently increasing flexural strength with increasing strain rate, fig. 5.

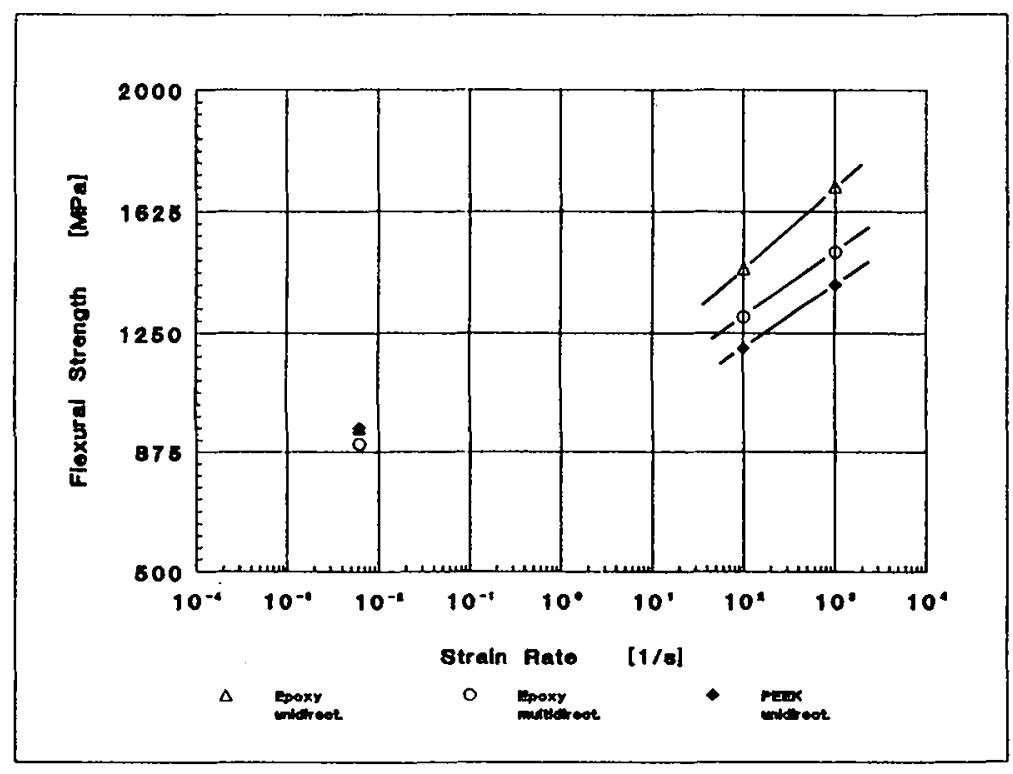

fig. 5: Flexural strength of the investigated CFRP as function of strain rate 
In detail the investigated expoxy-matrix materials show an increase in strength from $900 \mathrm{MPa}$ to approx. $1500 \mathrm{MPa}$ and a nearly constant elongation to fracture (.5\% to .7\%) within more than 5 magnitudes of strain rate. In comparison the PEEK-matrix material reaches a rate independent maximum strain of approx. $1.8 \%$ and a high rate strength of $1400 \mathrm{MPa}$, fig. 6. This behaviour seems to be comparable with some brittle metallic materials.
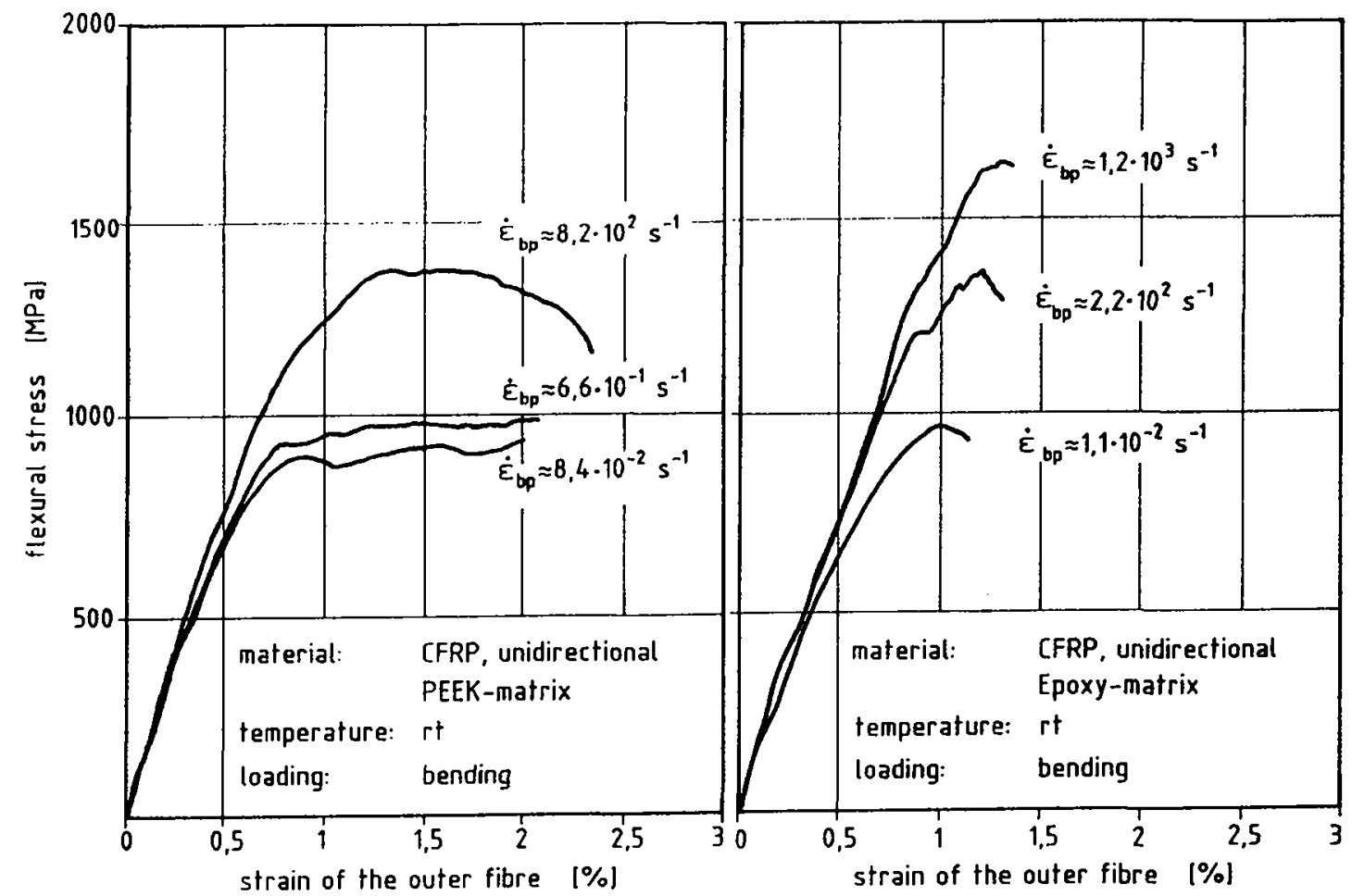

fig. 6: Stress-strain behaviour of the investigated unidirectional CFRP, epoxy matrix and PEEK matrix

This investigation delivers a number of input data for numerical simulation applications and it might give a basic safety in construction and design of structures and engines loaded in a high velocity area.

\section{Literature}

/1/ Harding, J.: Mechanical Behaviour of Composite Materials under Impact Loading. Int. Conf. on High Strain-Rate Phenomena in Materials, San Diego 1990, in press

12/ Amos, A.K.: Aerospace applications of materials at high strain rates. Proc. of 4 th Int. Conf. on the Mechanical Properties of Materials at High Rates of Strain, oxford 1989, The Institute of Physics, Bristol and New York, p. 534/552 
/3/ Welsh, L.M. and J. Harding: Effect of strain rate on the tensile failure of woven reinforced polyester resin composites. Proc. 3rd Int. Conf, on the Mechanical properties of Materials at High Rates of Strain, Oxford 1984, The Institute of Physics, Bristol and London, p. 39/46

/4/ Kumar, P. and B. Rai: Shear behaviour of unidirectional GFRP and CFRP at high strain rates. Proc. Int. Conf. on Mechanical and Physical Behaviour of Materials under Dynamic Loading, Ajaccio 1988, les editions de physique, Les Ulis Cedex, p. $97 / 103$

/5/ Chiem, C.Y. and M.Y. Liu: Contribution to the high strain rate behaviour of the high-polymer materials. proc. Int. Symp. on Intense Dynamic Loading and its Effects, Beijing 1986, Science Press, Beijing, p. 584/591

/6/ Harding, J., Y.L. Li, K. Saka and M.E.C. Taylor: Characterization of the impact of woven carbon fibre/epoxy laminates. Proc. 4th Int. Conf. on the Mechanical Properties of Materials at High Rates of Strain, oxford 1989, The Institute of Physics, Bristol and New York, p. 403/410

/7/ Harding, J., K. Saka and M.E.C. Taylor: The Effect of Strain Rate on the Tensile Failure of Woven-Reinforced Carbon/Glass Hybrid composites. Int. Conf. on Impact Loading and Dynamic Behaviour of Materials, Bremen 1988, DGM Informationsgesel1schaft mbH, Oberursel, Germany, p. 515/522

/8/ Behler, F.-J., S. Sikorski and E. Staskewitsch: Impact behaviour of carbon fibre reinforced composites under bend loading conditions. Poster presentation Int. Conf. on High Strain-Rate Phenomena in Materials 1990, in press

19/ Behler, F.-J. und B.-O. Reinders: Mechanical twinning of Armco-iron as function of strain-rate. Int. Conf. on Impact Loading and Dynamic Behaviour of Materials, Bremen 1988, DGM Informationsgesellschaft $\mathrm{mbH}$, Oberursel, Germany, p. 677/683 